\title{
ARCADE OF FLEXOR DIGITORUM SUPERFICIALIS MUSCLE: ANATOMICAL STUDY AND CLINICAL IMPLICATIONS
}

\section{ARCADA DO MÚSCULO FLEXOR SUPERFICIAL DOS DEDOS: ESTUDO ANATÔMICO E IMPLICAÇÕES CLÍNICAS}

\author{
Edie Benedito Caetano ${ }^{1}$, João José Sabongi Neto ${ }^{1}$, luiz Angelo Vieira ${ }^{1}$, Maurício Ferreira Caetano $^{2}$, José Eduardo de Bona ${ }^{1}$, \\ ThaIs MAYOR SimonatTo ${ }^{1}$
}

1. Faculdade de Ciências Médicas e da Saúde, Pontifícia Universidade Católica de São Paulo, Sorocaba, SP, Brazil.

2. Serviço de Cirurgia de Mão, Conjunto Hospitalar de Sorocaba, Sorocaba, SP, Brazil.

\begin{abstract}
Objective: The arcade of the flexor digitorum superficialis muscle (FDS) is an anatomical structure which has not yet been widely studied and is a site of nerve compression. The aim of this study was to analyze the arcade of the FDS muscle and its relations with the median and anterior interosseous nerves through anatomic dissections. Method: Fifty arms from 25 adult cadavers (21 males and 4 females) were dissected; 18 were previously preserved in formalin and glycerin and 7 fresh specimens were dissected in the Laboratory of Anatomy. Results: The arcade of the superficial flexor muscle was identified in all dissected limbs. The radial and humeral heads were present in all specimens, and the ulnar head in $16(32 \%)$. We identified two varieties of the arcade structure: a fibrous arcade in 32 specimens (64\%), and a muscular arcade in 11 specimens (22\%). In 4 specimens (8\%) the arcade was very fine and so transparent that the nerve could be seen within the arcade. In 3 forearms the arcade was considered irregular because of discontinuity between the fibers that comprised this structure. Conclusion: The fibrous arcade of the FDS muscle may be a potential cause of nerve compression of the median and interosseous anterior nerves. Level of Evidence IV; Case series.
\end{abstract}

Keywords: Muscle, skeletal/abnormalities. Nerve compression syndromes. Cadaver.

\section{RESUMO}

Objetivo: A arcada do músculo flexor superficial dos dedos (FSD) é um dos locais de compressão nervosa. Trata-se de uma estrutura anatômica ainda pouco conhecida. O objetivo do estudo foi analisar, através de dissecções anatômicas, a arcada do músculo FSD e suas relações com os nervos mediano e interósseo anterior. Método: Foram dissecados 50 membros superiores de 25 cadáveres adultos, 21 do sexo masculino e quatro do feminino, 18 previamente preservados em formol e glicerina e sete foram dissecados a fresco no Laboratório de Anatomia. Resultados: Identificamos a arcada do músculo flexor superficial em todos os membros dissecados. As cabeças radial e umeral estavam presentes em todos os antebraços e a cabeça ulnar foi encontrada em 16 (32\%). Identificamos dois tipos de arcada, arcada fibrosa em 32 (64\%) antebraços e arcada muscular em 11 (22\%). Em quatro espécimes (8\%), a arcada tinha constituição muito fina, sendo possível visualizar o nervo por transparência em seu interior. Em três antebraços, consideramos a arcada irregular, pois havia descontinuidade entre as fibras que a formavam. Conclusão: A arcada do músculo FSD de constituição anatômica fibrosa constitui um dos possíveis locais de compressão dos nervos mediano e interósseo anterior. Nível de Evidência IV; Série de casos.

Descritores: Músculo esquelético/anormalidades. Síndromes de compressão nervosa. Cadáver.

Citation: Caetano EB, Sabongi Neto JJ, Vieira LA, Caetano MF, Bona JE, Simonatto TM. Arcade of flexor digitorum superficialis muscle: anatomical study and clinical implications. Acta Ortop Bras. [online]. 2018;26(1):36-40. Available from URL: http://www.scielo.br/aob.

\section{INTRODUCTION}

The median nerve, which is formed by the junction of the lateral and medial fasciculi of the brachial plexus, originates in nerve fibers within the spinal roots of C5 to T1. In the distal region of the arm, this nerve passes between the brachialis muscle and the intermuscular septum, continues through the cubital fossa, and passes through the bicipital aponeurosis (lacertus fibrosus). It continues its trajectory, passing between the superficial and deep head of the pronator teres muscle, then enters the arcade formed by the humeral, ulnar, and radial insertions of the flexor digitorum superficialis muscle. ${ }^{1-3}$ Pronator syndrome is one of three compressive syndromes which affect the median nerve; the other two are anterior interosseous nerve syndrome and the much more common carpal tunnel syndrome. Consequently, whenever a patient presents symptoms of compression of the median nerve, carpal tunnel syndrome should be initially suspected. ${ }^{1}$

The term pronator syndrome was first used by Seyffarth ${ }^{4}$ in 1951 to describe compressive neuropathy of the median nerve in the

All authors declare no potential conflict of interest related to this article. 
proximal forearm. Classically, pronator syndrome presents as paresthesia in the distribution of the median nerve and pain in the forearm, while proximal weakness may occur in the flexor-pronator muscle group. This may be confused with carpal tunnel syndrome, because the clinical profile may be very similar. ${ }^{5}$ The absence of pain at night and decreased sensitivity in the area of innervation of the palmar cutaneous branch of the median nerve may be useful to distinguish the two syndromes. 5,6 There are four possible sites where compression of the median nerve may occur in pronator syndrome (from proximal to distal): 1) the Struthers ligament, 2) the bicipital aponeurosis, 3) the arch formed between the proximal muscle insertions of the superficial flexor muscle, and 4) between the humeral and ulnar heads of the pronator teres muscle. Some provocative tests can be used to differentiate the location of nerve compression, but their reliability in diagnosis is limited. ${ }^{1,3,7}$ Tinel's sign can be useful in finding the location of the compression. The results of electrophysiological exams are consistent with nerve compression at the elbow, suggesting but not confirming the exact location of the compression. ${ }^{8-10}$

Only surgical exploration of the nerve in the cubital fossa can identify the structure responsible for the nerve compression. 3,11

The flexor digitorum superficialis (FDS) is the largest muscle in the forearm. It forms an intermediary muscular layer in the forearm between the superficial and deep groups. The median nerve and ulnar artery enter the forearm through an archway formed by the insertions of this muscle's radial and humero-ulnar heads. However, the relation between the median nerve and the radial and humero-ulnar head of the superficial flexor muscle may be subjected to anatomical variations. ${ }^{8,9,12,13}$ The objective of this study was to use anatomical dissections to analyze the relationship between the arcade of the superficial flexor muscle and the median nerve, thus contributing to a better understanding of nerve compression at this site.

\section{METHODS}

To conduct this study 50 forearms from 25 adult cadavers (21 men and 4 women) belonging to the FCMS Laboratory at PUCSP were dissected. Ages ranged from 28 to 77 years, 27 cadavers were white and 23 non-white, 18 had been previously preserved in formaldehyde and glycerin, and 7 were fresh. Forearms deformed by trauma, congenital malformations, and scars were excluded. No sign of muscular atrophy was identified in the dissected forearms. With the elbow flexed and the forearm supine, the dissection was performed through a midline incision along the entire forearm and lower third of the upper arm, and two flaps including the skin and subcutaneous tissue were reflected to the radial and ulnar sides, respectively. This same process was repeated for the fascia of the arm and forearm, exposing all the musculature. We analyzed the proximal origins of the superficial flexor muscle, the presence of the radial, humeral, and ulnar heads, the anatomical constitution of the supinator arch, and the distance from the apex of the arch to the medial epicondyle. These dissections were also intended to identify other anatomic sites that could be responsible for compression of the median nerve, such as the Struther's ligament, bicipital aponeurosis, and between the humeral and ulnar heads of the pronator teres muscle. All of the anatomical variations were identified, recorded, and photographed. During certain stages of the dissection, we used a Keeler 2.5x magnifying glass. The study was approved by the institutional review board under process number 1,611,295.

\section{RESULTS}

We identified the presence of the arcade in the dissected arms. The radial head of the FDS muscle was identified in 50 forearms (100\% of specimens), with extension ranging from 2.5 to $7.5 \mathrm{~cm}$ (mean: $5.2 \mathrm{~cm}$ ). The humeral head was also identified in all the forearms, with insertion in the medial epicondyle, beside the pronator teres muscle. (Figures $1 \mathrm{~A}$ and $1 \mathrm{~B}$ ) The ulnar head was identified in only 16 forearms (32\%), inserting into the area surrounding the coronoid process of the ulna. (Figure 1B) A fibrous arcade was identified in 32 forearms (64\%), in 21 with transverse anatomical conformation (Figures 2A and 2B), in 5 with V-shaped conformation (Figure 3A), and oblique in 6. (Figure 3B) A muscular arcade was recorded in 11 specimens $(22 \%)$, with transverse conformation in 8 (Figure 4A) and oblique in 3. (Figure 4B) The arcade was transparent in 4 forearms $(8 \%)$, and was so fine that the nerve could be seen within (Figures $5 \mathrm{~A}$ and $5 \mathrm{~B}$ ). In 3 (6\%) forearms the arcade was considered irregular because there was discontinuity between the fibers that formed it. (Figure 6A) Proximity seen in all specimens between the arcade and median nerve. (Figure 6B) In all specimens we observed that the median nerve was in contact with the arcade; no structure or even any space was present between the nerve and the arcade. (Figure $6 \mathrm{~B})$ In terms of the relationship between the anterior interosseous nerve and the arcade, we noted that there was often some space between its branches and the arcade, since it was located posterior to the median nerve (since it originates in nerve fibers posterior to the median nerve). (Figures $1 \mathrm{~B}$ and $2 \mathrm{~A}$ ) The average distance between the point of the arcade that rested on the median nerve and the medial epicondyle was $7.5 \mathrm{~cm}(6.4-8.2 \mathrm{~cm})$. The width of the arcade ranged from 3 to $6 \mathrm{~cm}$ (mean: $4.2 \mathrm{~cm}$ ). The anterior interosseous nerve originated from the median nerve proximal to the arcade in all forearms. (Figures 3 and 4) The distal arch of the FDS muscle was studied in 30 forearms; this structure was always muscular (Figures 7A and 7B), positioned an average of $3.8 \mathrm{~cm}$ proximal to the wrist crease overlying the median nerve in
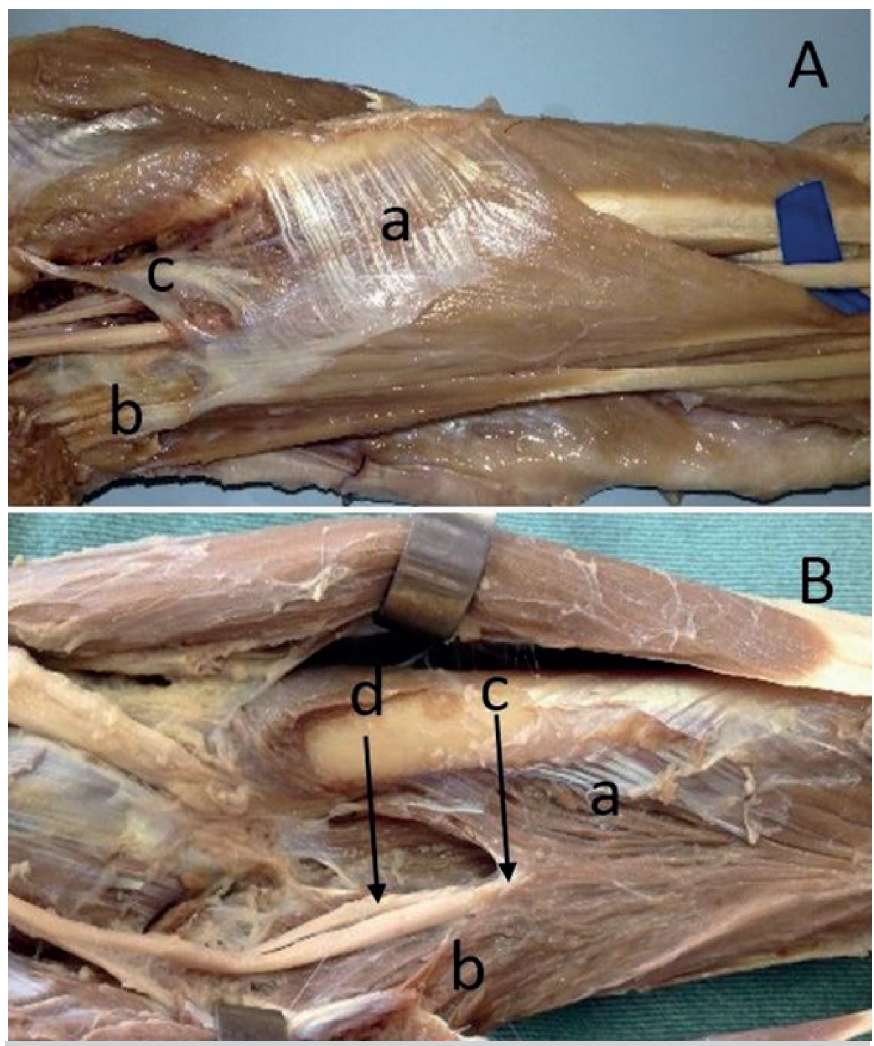

Figure 1. A) The radial (a) and (b) humeral heads were identified in 50 forearms. The ulnar head (c) was identified in only 16 forearms. B) absent ulnar head. Median nerve (c). Anterior interosseous nerve (d). 
all the forearms, and overlying the palmar cutaneous branch of the median nerve in 18 of the 30 forearms. (Figure 7B) Although the median and cutaneous palmar nerves were adjacent to each other, they were not seen to be so close that this could be the cause of nerve compression.
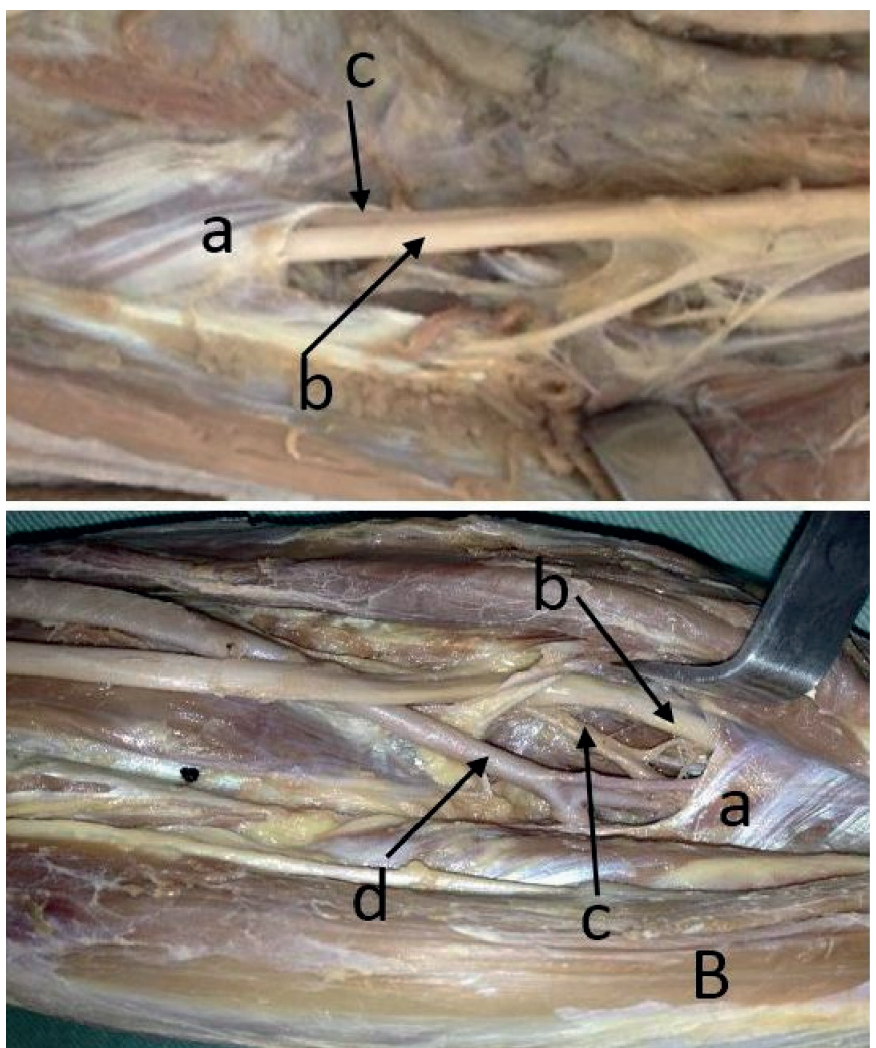

Figure 2. (A e B) Transverse fibrous arcade identified in 19 forearms (a) Median nerve (b). Anterior interosseous nerve (c). Ulnar artery (d).

\section{DISCUSSION}

Some authors disagree that compression in places other than the humeral and ulnar heads of the pronator teres muscle should be called pronator syndrome. ${ }^{1,7,14}$ Tubbs et al. ${ }^{14}$ consider this denomination incorrect when compression occurs through the arcade of the FDS muscle, the bicipital aponeurosis, or the Struthers ligament, and suggests that the correct name would be proximal compressive neuropathies of the median nerve rather than pronator syndrome. These authors reported that patients with compression caused by the pronator teres muscle complain that the symptoms of pain and paresthesia arise after intense repetitive activities involving pronation and supination, and that in their studies involving 60 dissected forearms they found that the extension of the elbow compressed the nerve more through the arcade of the overlying FDS muscle. Pronation and supination movements do not alter the relationship between the median nerve and FDS muscle arcade. In the cases we dissected, we recognized the existence of an important limitation. The dissections extended from the arm to the hand, since we analyzed the relation between the median nerve and arcade of Struthers, bicipital aponeurosis, and between the humeral and ulnar heads of the pronator teres muscle and the FDS muscle arcade. In this procedure all fascial structures were sectioned, and consequently the tension created by these structures was eliminated; we noted that even in the fresh cadavers used, the flexion and extension movements and pronation and supination


Figure 3. A) A fibrous, V-shaped arcade (a) was identified in 5 limbs. B) A fibrous, oblique arcade was identified in 6 limbs.

of the forearm do not alter the relationship between the arcade of the FDS muscle and the median nerve. Hartz et al. ${ }^{9}$ reported that based on their experience, compression of the median nerve caused by the bicipital aponeurosis resulted in pain that spread diffusely along the volar surface of the forearm, while compression from the arcade of the FDS muscle resulted in very localized pain. Wertsch and Melvin ${ }^{15}$ reproduced pain in the proximal forearm in patients with compression of the median nerve under the arcade of the FDS muscle through flexion of the middle finger against resistance. Rengachary ${ }^{11}$ states that although several clinical tests have been described to differentiate the location of nerve compression, it is not possible to clinically differentiate the exact location where compression occurs, and that any surgical procedure that does not explore all potential compression sites is incomplete.

Previous studies attempting to establish a link between the arcade of the FDS muscle and nerve compression have been controversial. Olehnik et al. ${ }^{16}$ reported operating on 39 forearms with symptoms suggesting compression of the median nerve in the proximal forearm; 19 patients had previously undergone carpal tunnel release, but the symptoms persisted. In 22 of the 39 forearms these authors identified that the compression was caused by the FDS muscle arcade, in 13 by the pronator teres muscle, and in 4 by both. Hartz et al. ${ }^{9}$ reported that 36 patients with a clinical diagnosis of pronator teres syndrome were seen over a period of seven years; 36 surgical procedures were performed in 32 forearms, and in 12 the presence of the fibrous arcade of the FDS muscle was identified as compressing the median nerve. In contrast, Johnson and Spinner ${ }^{2}$ observed compression in the arcade of the FDS muscle in only 7 of 51 cases operated; in 2 cases the compression was caused by 

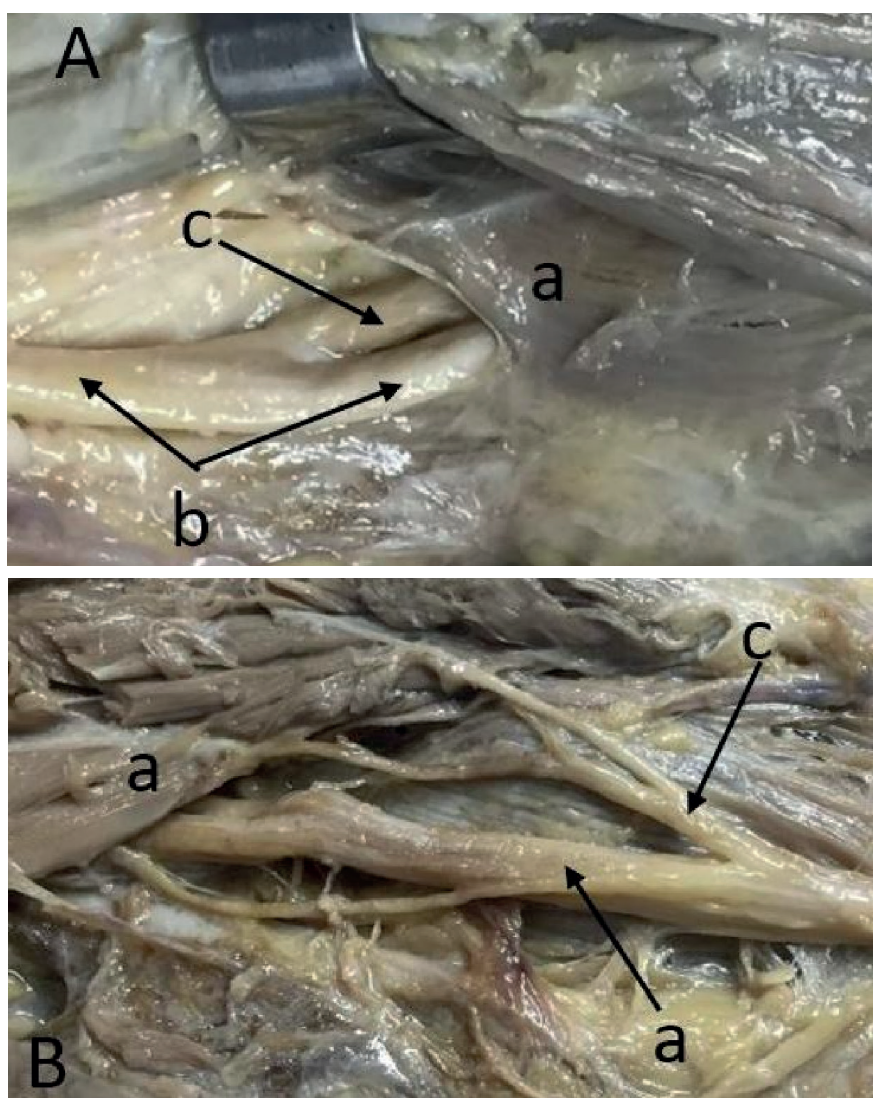

Figure 4. A) A muscular, transverse arcade (a) was identified in 8 limbs. B) A fibrous, oblique arcade was identified in 3 limbs. Median nerve (b). Anterior interosseous nerve (c)
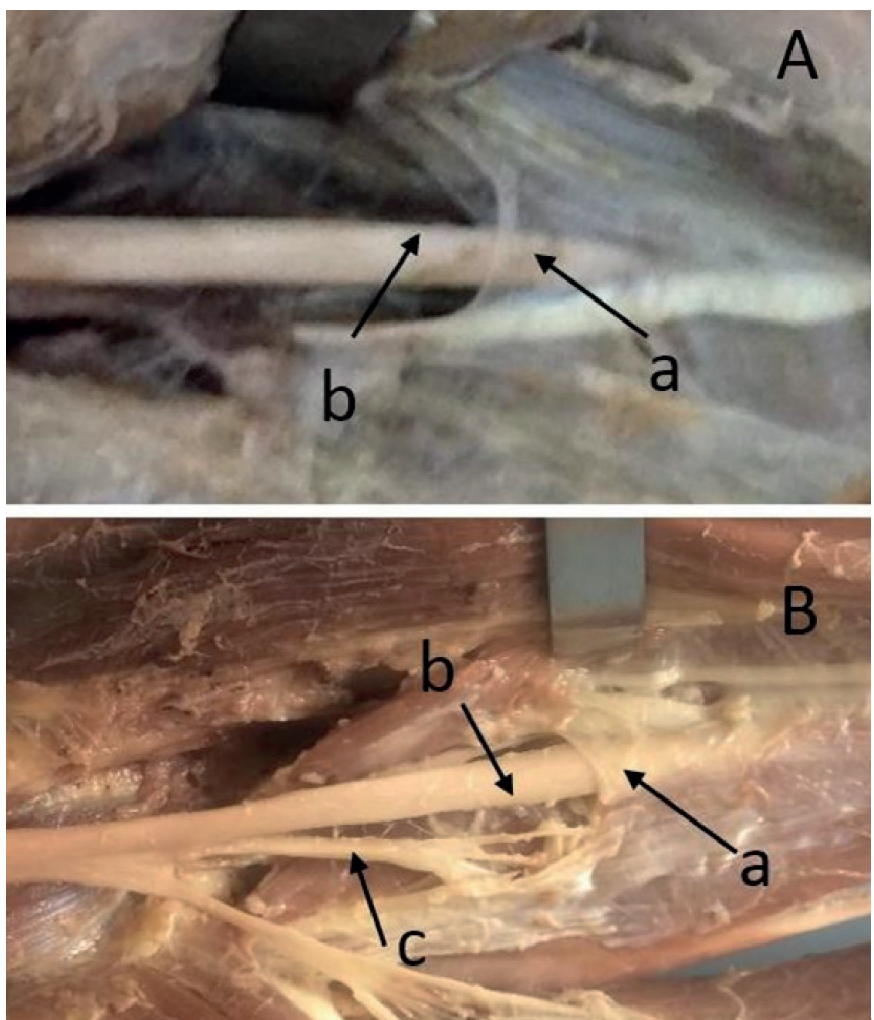

Figure 5. (A e B) A transparent and very fine arcade (a) Note visibility of the median nerve (b) within the arcade. Anterior interosseous nerve (c).
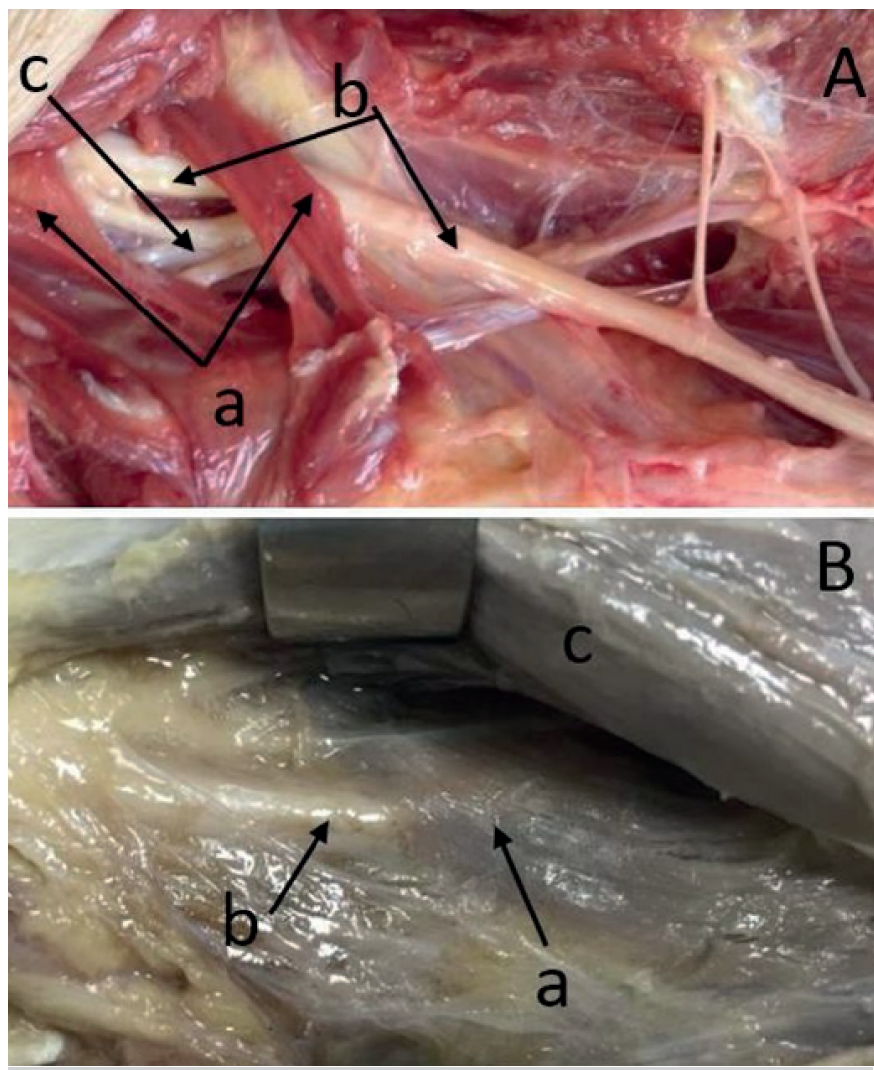

Figure 6. A) Irregular arcade (a) with discontinuity between constituting fibers. B) Proximity between the arcade and median nerve was seen in all specimens. Median nerve (b). Anterior interosseous nerve (c). Pronator teres muscle (d).

the bicipital aponeurosis, and in 39 by the pronator teres muscle. Park et al..$^{17}$ reported that 11 patients with anterior interosseous syndrome were treated with surgical exploration, and that the most common structure responsible for nerve compression was a fibrous band of the FDS muscle.

Few descriptions of the anatomical formation of the FDS muscle arcade can be found in the literature. Bilecenoglu et al. ${ }^{18}$ dissected 30 limbs from 15 cadavers fixed in formalin, and in $97.7 \%$ of cases found the existence of two heads of the superficial flexor muscle forming an arcade where the median and anterior interosseous nerves passed. In one of these 30 limbs the radial head was not identified, and the arcade was consequently nonexistent. Dellon and Mackinnon ${ }^{7}$ identified the FDS muscle in 31 dissected arms. In 4 specimens, these authors found that the muscle originated only in the medial epicondyle of the humerus. In 27 specimens there was also insertion in the coronoid process of the ulna, and in 10 specimens there was a third head originating from the radial diaphysis. In our study we identified the radial head of the FDS muscle in all forearms, with its dimensions varying widely in length from 2.5 to $7.5 \mathrm{~cm}$ (mean: $5.2 \mathrm{~cm}$ ). Similarly, the humeral head was seen in all specimens, with insertion in the medial epicondyle beside the pronator teres muscle. The ulnar head was identified in only 16 forearms (32\%), inserting into the area surrounding the coronoid process of the ulna.

Guo and Wang ${ }^{19}$ dissected 38 cadaver arms to help clarify which portion of the arcade should be sectioned in each case to decompress the median nerve. These authors identified two types of FDS muscle arcade: one distinct fibrous arcade composed of fibrous tissue in which the entrance was clearly evident, and another indistinct arcade with vertical muscular fibers intermixed with the 

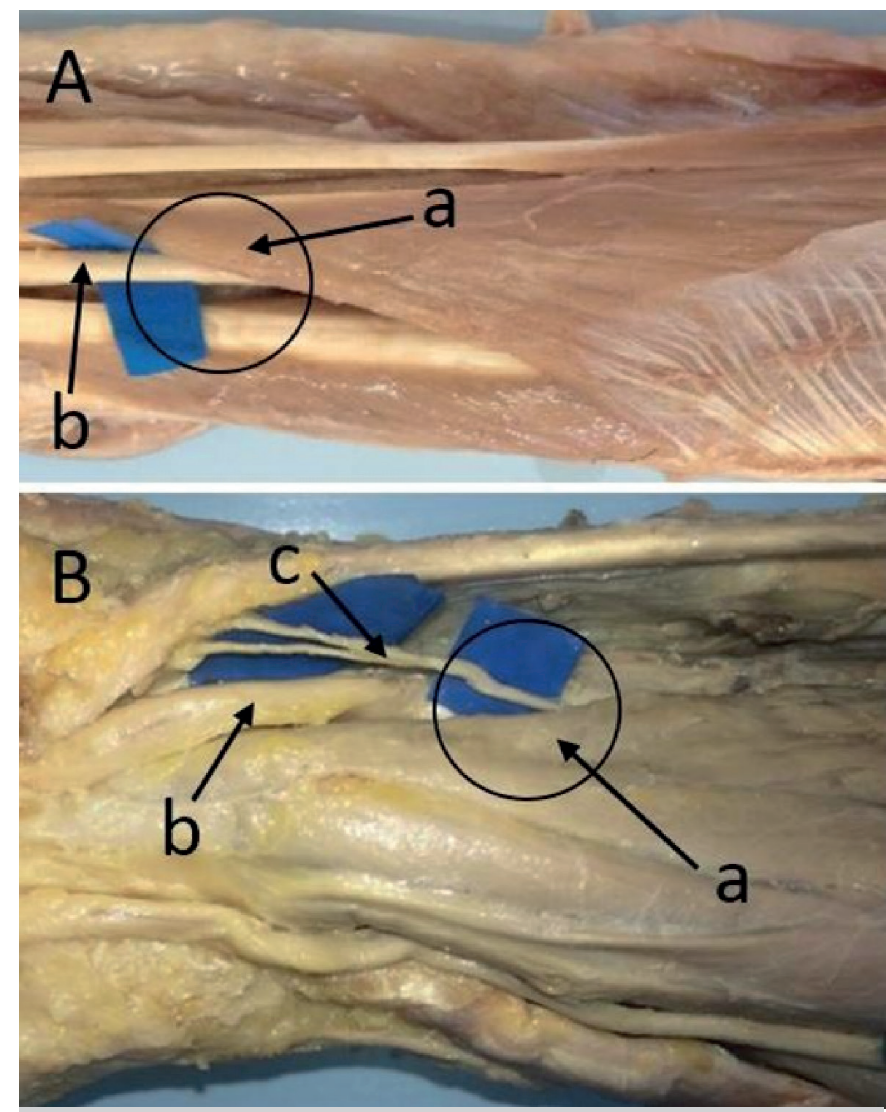

Figure 7. A) Distal arcade of the FDS muscle; (a) always muscular, positioned overlying the median nerve (b) in all the forearms. B) overlying the palmar cutaneous branch of the median nerve (c) in 18 of the 30 forearms.

overlying fascia. A distinct FDS muscle arcade was identified in only 16 forearms (42\%). In 22 specimens (58\%), the arcade was blurry, and of these the presence of muscular tissue made it difficult to see the arcade in 17 specimens (77\%), requiring further dissection to visualize this structure. In contrast, in our dissections the following procedure was followed: after evaluating the relationship between the median nerve and the humeral and ulnar heads of the pronator teres muscle, we detached the insertion of this muscle from the radial diaphysis so that when the muscle was raised there were no difficulties in visualizing the arcade of the FDS muscle. Tubbs et al. ${ }^{14}$ dissected 60 forearms from 30 prepared cadavers and found a tendinous arcade in 45 specimens (75\%) and a muscular arcade in 15 (25\%). Dellon and Mackinnon ${ }^{7}$ identified the presence of a fibrous arcade in 11 of 31 dissected limbs (36\%). Johnson et al. ${ }^{2}$ dissected 40 preserved cadavers, and in 12 (30\%) identified a fibrous arcade, in the proximal margin of the FDS muscle in 10 (25\%). (Table 1)

Tubbs et al. ${ }^{14}$ reported identifying in 60 dissected limbs that the anterior interosseous nerve originated proximal to the arcade of the superficial flexor muscle. Our findings confirm those of Tubbs et al., ${ }^{14}$ since we identified the anterior interosseous nerve as originating proximally to the arcade in all specimens; in many cases it was very close to the arcade but not distal to it, and the branching of the anterior interosseous nerve proximal to the arcade was recorded in only 18 specimens (36\%). We identified a fibrous arcade in 32 forearms (64\%), a muscular arcade in $11(22 \%)$, and a transparent arcade in 4 (8\%); in this latter case, the arcade was very fine and transparent and the nerve could consequently be seen within the arcade. In three (6\%) forearms we considered the arcade irregular, since there was discontinuity between the fibers that comprised it.

Table 1. Summary of the literature addressing different rates of occurrence
for the fibrous arcade of the FDS muscle.
\begin{tabular}{c|c|c|c|c|c} 
Year & Authors & Type of study & Forearms & $\begin{array}{c}\text { Fibrous } \\
\text { arcade }\end{array}$ & Percentage \\
\hline 1979 & Johnson et al. $^{2}$ & Anatomical & 40 & 12 & $30 \%$ \\
\hline 1981 & Hartz et al. $^{9}$ & Clinical (surgical) & 32 & 12 & $33.5 \%$ \\
\hline 1987 & $\begin{array}{c}\text { Dellon and } \\
\text { Mackinnon }\end{array}$ & Anatomical & 31 & 11 & $36 \%$ \\
\hline 2010 & Tubbs et al. $^{14}$ & Anatomical & 60 & 45 & $75 \%$ \\
\hline 2014 & $\begin{array}{c}\text { Guo and } \\
\text { Wang }\end{array}$ & Anatomical & 38 & 16 & $42 \%$ \\
\hline
\end{tabular}

\section{CONCLUSION}

The anatomically fibrous arcade of the FDS muscle is one potential site of compression of the median and anterior interosseous nerves.

AUTHORS' CONTRIBUTIONS: Each author made significant individual contributions to this manuscript. JEB (0000-0002-2416-7281)* and TMS (0000-00020654-5373)* conducted the bibliographic survey and anatomical dissections; JJSN (0000-0002-0554-1426)* analyzed the results and conducted the anatomical dissections; LAV (0000-0003-4406-2492)* drafted the article and created the photographic documentation; MFC (0000-0003-0994-2128** conducted the anatomical dissections and created the photographic documentation; EBC (0000-0003-4572-3854)* participated in all dissections, the drafting and review of the article, analysis of the results, intellectual concept of the article, and preparation of the entire research project. *ORCID (Open Researcher and Contributor ID).

\section{REFERENCES}

1. Spinner M. Injuries to the major branches of the peripheral nerves of the forearm. Philadelphia: Saunders; 1978.

2. Johnson RK, Spinner M, Shrewsbury MM. Median nerve entrapment syndrome in the proximal forearm. J Hand Surg Am. 1979;4(1):48-51.

3. Gainor BJ. The pronator compression test revisited. A forgotten physical sign. Orthop Rev. 1990;19(10):888-92

4. Seyffarth H. Primary myoses in the M. pronator teres as cause of lesion of the N. medianus (the pronator syndrome). Acta Psychiatr Neurol Scand Suppl. 1951;74:251-4

5. Dang AC, Rodner CM. Unusual compression neuropathies of the forearm, part II: median nerve. J Hand Surg Am. 2009;34(10):1915-20.

6. Fuss FK, Wurzl GH. Median nerve entrapment. Pronator teres syndrome. Surgical anatomy and correlation with symptom patterns. Surg Radiol Anat. 1990;12(4):267-71.

7. Dellon AL, Mackinnon SE. Musculoaponeurotic variations along the course of the median nerve in the proximal forearm. J Hand Surg Br. 1987;12(3):359-63.

8. Morris $\mathrm{HH}$, Peters $\mathrm{BH}$. Pronator syndrome: clinical and electrophysiological features in seven cases. J Neurol Neurosurg Psychiatry. 1976;39(5):461-4.

9. Hartz CR, Linscheid RL, Gramse RR, Daube JR. The pronator teres syndrome: compressive neuropathy of the median nerve. J Bone Joint Surg Am. 1981;63(6):885-90.

10. Werner CO, Rosén I, Thorngren KG. Clinical and neurophysiologic characteristics of the pronator syndrome. Clin Orthop Relat Res. 1985;(197):231-6.
11. Rengachary SS. Entrapment neuropathies. In: Wilkinds $\mathrm{RH}$, Rengachary SS, editors. Neurosurgery. New York: McGraw-Hill; 1985. p. 1771-95.

12. Kopell HP, Thompson WA. Pronator syndrome: a confirmed case and its diag nosis. N Engl J Med. 1958;259(15):713-5.

13. Sunderland S. Nerves and nerve injuries. 2a. ed. Edinburgh: Churchill Livingstone; 1978 14. Tubbs RS, Marshall T, Loukas M, Shoja MM, Cohen-Gadol AA. The sublime bridge: anatomy and implications in median nerve entrapment. J Neurosurg. 2010;113(1):110-2.

15. Wertsch JJ, Melvin J. Median nerve anatomy and entrapment syndromes: a review. Arch Phys Med Rehabil. 1982;63(12):623-7.

16. Olehnik WK, Manske PR, Szerzinski J. Median nerve compression in the proximal forearm. J Hand Surg Am. 1994;19(1):121-6.

17. Park IJ, Roh YT, Jeong C, Kim HM. Spontaneous anterior interosseous nerve syndrome: clinical analysis of eleven surgical cases. J Plast Surg Hand Surg. 2013;47(6):519-23.

18. Bilecenoglu B, Uz A, Karalezli N. Possible anatomic structures causing entrapment neuropathies of the median nerve: an anatomic study. Acta Orthop Belg 2005;71(2):169-76.

19. Guo B, Wang A. Median nerve compression at the fibrous arch of the flexor digitorum superficialis: an anatomic study of the pronator syndrome. Hand (NY). 2014;9(4):466-70. 